\title{
Resectable Duodenal Carcinoma
}

National Cancer Institute

\section{Source}

National Cancer Institute. Resectable Duodenal Carcinoma. NCI Thesaurus. Code

C27323.

Carcinoma of the duodenum amendable to surgical removal. 